\title{
Transatlantica
}

Revue d'études américaines. American Studies Journal

\section{François Weil, Histoire de New York.}

Paris, Fayard, 2000, 377 pp.

\section{Pierre Gervais}

\section{(2) OpenEdition}

Journals

Édition électronique

URL : http://journals.openedition.org/transatlantica/357

DOI : $10.4000 /$ transatlantica.357

ISSN : $1765-2766$

Éditeur

AFEA

Référence électronique

Pierre Gervais, « François Weil, Histoire de New York. », Transatlantica [En ligne], 1 | 2001, mis en ligne le 23 mars 2006, consulté le 29 avril 2021. URL : http://journals.openedition.org/transatlantica/357 ;

DOI : https://doi.org/10.4000/transatlantica.357

Ce document a été généré automatiquement le 29 avril 2021.

\section{(c) (†) $९$}

Transatlantica - Revue d'études américaines est mis à disposition selon les termes de la licence Creative Commons Attribution - Pas d'Utilisation Commerciale - Pas de Modification 4.0 International. 


\title{
François Weil, Histoire de New York.
}

\author{
Paris, Fayard, 2000, 377 pp.
}

\author{
Pierre Gervais
}

Ecrire un ouvrage «tous publics » est un exercice risqué pour l'historien; comment faire simple et lisible sans tomber dans le schématisme et l'approximation? Le travail de François Weil fournit une des réponses possibles. L'approche par multiples vignettes, quasi pointilliste, d'un sujet, la ville de New York, qui fournit il est vrai plus que d'autres matière à anecdotes, permet d'obtenir un effet d'accumulation aussi plaisant à la lecture qu'instructif au bout du compte. Le matériau est présenté globalement en quatre périodes, avec chacune sa couleur particulière. "Provinciale » (1620-1820), puis «reine du nouveau monde» (1820-1890), incarnation des «modernités métropolitaines » (1890-1940), enfin «capitale du siècle américain », la ville au bord de l'Hudson est décrite avec une évidente sympathie, et d'abord dans ce qui fait sa force, réelle ou imaginaire. La structure économique, l'activité culturelle et intellectuelle, la diversité "ethnique», les efforts architecturaux, les inégalités sociales, sont les aspects les plus systématiquement présentés, sans doute parce qu'ils contribuent tous peu ou prou à expliquer et sous-tendre tel ou tel aspect de la fascination sans réticence avec laquelle New York est considérée aujourd'hui de ce côté-ci de l'Atlantique. Autre effort louable, celui consistant à souligner ces éléments de puissance qui font de New York, malgré tout, une ville américaine, comme les activités coloniales (la première partie, qui porte sur New York la hollandaise et son héritage pré-révolutionnaire, est l'une des plus réussies du livre), ou les efforts réformistes de la "métropole moderne", ou le développement des organes de production culturelle de masse, des magazines à la télévision. L'abondance des illustrations (avec une petite tendance à l'économie sur la fin de l'ouvrage), et surtout, là encore, leur valeur illustrative, sont également à souligner, dans un domaine où la carte postale vide de sens fait trop souvent recette. La vie politique en revanche est peu présente, malgré quelques pages sur Tammany Hall, Fiorello La Guardia ou l'extrême-gauche des années 1930; les arcanes des débats municipaux ne se prêtaient certes guère à une présentation claire. Pour cette même raison sans doute, les abondants débats historiographiques entre historiens spécialistes de la chose urbaine ont été laissés de côté ; un essai bibliographique en fin d'ouvrage permet cependant de découvrir les 
principaux livres sur la question. L'historien professionnel regrettera aussi l'absence d'annexes statistiques, qui auraient permis au lecteur intéressé d'avoir une vue d'ensemble parfois difficile à reconstruire à partir des éclairages variés offerts par le texte. Mais rien de tout cela ne touche à l'essentiel d'un projet qui était moins celui d'une synthèse érudite que d'une introduction à la fois sérieuse et attrayante. Le seul vrai reproche - au sens où il porte précisément sur l'efficacité pédagogique de cette introduction à la «ville-empire»-, porte sur les cartes, ou plutôt sur leur quasi absence, hors quelques cartes anciennes et une série de schémas portant sur l'ensemble régional new-yorkais. Gageons que l'auteur aura à coeur d'introduire quelques plans détaillés de Manhattan, voire de Brooklyn, dans la réédition de ce travail, et de corriger ainsi la seule faiblesse sérieuse d'un travail par ailleurs méritoire. Car au bout du compte, grâce en particulier à la vivacité de la narration, le livre de François Weil instruit en distrayant, ce qui n'est pas si facile; l'Histoire de New York permet de découvrir les grands traits de l'épopée économique et sociale d'une des ville les plus célèbres du monde.

INDEX

Thèmes : Recensions 